\title{
Celulasas presentes en el tracto digestivo del camarón Litopenaeus vannamei
}

\author{
Claudia Segovia-Salcedo ${ }^{1}$, Alexandra Narváez-Trujillo ${ }^{2}$, Fernando Espinoza-Fuentes ${ }^{3}$ \\ ${ }^{1}$ Departamento de Ciencias de la Vida. Escuela Politécnica del Ejército. \\ Sangolquí, Ecuador. mcsegovia@espe.edu.ec \\ ${ }^{2}$ Laboratorio de Biotecnología Vegetal, Escuela de Ciencias Biológicas, \\ Pontificia Universidad Católica del Ecuador. Quito, Ecuador. anarvaez@puce.edu.ec \\ ${ }^{3}$ Universidad Espíritu Santo. Guayaquil, Ecuador.
}

Recibido: 2015-08-07; aceptado: 2015-10-12

\begin{abstract}
RESUMEN.- Las celulasas han sido clasificadas como endoglucanasas responsables de degradar celulosa, lo que le proporciona gran importancia en los procesos de la cadena alimentaria. Las celulasas y enzimas relacionadas son utilizadas ampliamente en varios procesos industriales. La celulosa es utilizada como una fuente nutricional por varios organismos, inicialmente se pensaba que únicamente microorganismos podrían degradarla, pero en la actualidad se ha encontrado celulasas en varios grupos de animales. En este trabajo, presentamos la detección de celulasas en extractos obtenidos del camarón Litopenaeus vannamei. En los ensayos se utilizaron individuos adultos y de los diferentes subestadios de L. vannamei colectados en los estanques de cría de las camaroneras de la Península de Santa Elena y Muisne, en las provincias de Santa Elena y Esmeraldas, respectivamente. Los hepatopáncreas, los estadios larvarios y los intestinos fueron homogeneizados en un homogeneizador Braun-Melsungen. Para la identificación de la celulasa, se utilizó como sustrato carboximetil celulosa (CMC) de mediana viscosidad. Para medir su actividad se añadió ácido 3,5 dinitrosalicílico (DNS). La actividad de la celulasa se determinó en base en la cantidad de los grupos reductores liberados. Para intentar determinar el origen sea endógeno o microbiano de las celulasas identificadas, se sometieron las muestras de adultos a antibióticos.
\end{abstract}

En el subestadio zoea 3, se identificó una celulasa con un rango de pH óptimo entre pH 6.5 y pH 9.5. En las muestras de hepatopáncreas del camarón adulto se determinaron dos pH óptimos: uno en el rango ácido (pH 4-6) y otro en el rango básico ( $\mathrm{pH}$ 10-11) lo cual sugiere la presencia de dos celulasas diferentes. En el intestino se observó actividad únicamente en el pH ácido ( $\mathrm{pH}$ 4-6). La actividad celulolítica detectada en el desarrollo ontogénetico del camarón fue baja e inestable, una condición reportada también en el análisis comparativo de enzimas digestivas en otras cuatro especies de crustáceos. La actividad relativa de las dos enzimas del hepatopáncreas es similar y cada una de estas tienen una actividad cuatro veces mayor a la encontrada en el intestino. Estos resultados indican la presencia de dos celulasas presentes en el hepatopáncreas y se sugiere que una de ellas (con pH óptimo ácido) podría ser transportada desde el hepatopáncreas al intestino, aunque los datos no son concluyentes. En el caso de la celulasa con actividad a pH básico (10.5) puede tratarse de una celulasa producida de manera endógena por el camarón. Los datos reportados en este estudio sobre las capacidades de producción enzimática del camarón puede ser la base para futuros proyectos de investigación cuyo objetivo sea optimizar los procedimientos de cultivo del camarón.

PALABRAS CLAVES: Celulasas, crustáceos, digestión, Ecuador, Litopenaeus vannamei.

ABSTRACT.- Cellulases have been classified as endoglucanases. This is the only enzyme capable of degrading cellulose, which gives an immense importance in the processes of the food chain, being cellulose the most abundant source of carbon on earth. Cellulases and related enzymes are widely used in various industrial processes. Cellulose is used as a nutritional source for several organisms, initially it was thought that only microorganisms may degrade this polymer however cellulases have been reported in many animal groups. In this paper, we present the preliminary identification and characterization of cellulases in the shrimp Litopenaeus vannameiduring its larval and adult stages. In adults and $\mathrm{f}$ different sub-stages of L. vannamei were collected in culture tanks in comercial shrimp farms in the Santa Elena Peninsula and Muisne, in the provinces of Esmeraldas and Santa Elena, respectively. The hepatopancreas, larval stages and intestines were 
homogenized in a Braun-Melsungen homogenizer. Carboxymethyl cellulose (CMC) of medium viscosity was used as a substrate. To measure enzymatic activity 3,5 dinitrosalicylic acid (DNS) was added. The cellulase activity was determined based on the amount of reducing groups released. To try to determine the presence of endogenous cellulases, that is produced by shrimp, samples were submitted to antibiotics and later assayed. In sub-stage zoeal 3, a cellulase with an optimal $\mathrm{pH}$ range between $\mathrm{pH} 6.5$ and $\mathrm{pH} 9.5$ was determined. In samples of adult shrimp hepatopancreas two optimum $\mathrm{pH}$ were determined: one in the acid range $(\mathrm{pH}$ 4-6) and one in the basic range ( $\mathrm{pH} 10-11)$, while in the intestine only one in an acidic $\mathrm{pH}$ range (pH 4-6) was determined. The cellulase activity detected in the ontogenetic development of the shrimp was low and unstable, a condition also reported in the comparative analysis of digestive enzymes in four other species of crustaceans. The relative activity of the two enzymes is similar in the hepatopancreas and each of these have an activity four times greater than that found in the intestine. These results suggest the presence of two possible cellulases, one could be transported from the hepatopancreas into the intestine but more tests are needed to get more conclusive results. The cellulase activity at basic $\mathrm{pH}$ (10.5) may be a cellulase produced endogenously by the shrimp. The data reported in this study of enzyme production capabilities shrimp can be the basis for future research projects aimed at optimizing procedures shrimp farming.

KEYWORDS: Celullases, crustacean digestión, Ecuador, Litopenaeus vannamei

\section{INTRODUCCIÓN}

En los últimos 20 años el progreso en la ingeniería genética de las enzimas y la tecnología de fermentación, han permitido el desarrollo de aplicaciones enzimáticas en las áreas industriales que van desde la fabricación de detergentes más eficientes y amigables con el ambiente, hasta aplicaciones en la industria textil, del cuero, de alimentos, cosméticos, productos médicos y también como herramientas para proyectos de investigación (Galante y Formantici, 2003). Esto ha llevado a que el gasto en la utilización de enzimas se cotice en varios millones de dólares a nivel mundial y que los proyectos de investigación en busca de nuevas enzimas aptas para ser utilizadas en la industria se multipliquen (Beilen y Li, 2002).

Las celulasas han sido clasificadas en: endoglucanasas, que se encargan de la destrucción de los enlaces 1,4- $\beta$-glucosídicos actuando en la hidrólisis en el interior de la cadena; luego están las exo-celobiosas que son exoglucanasas, encargadas de hidrolizar los enlaces 1,4- $\beta$ - glucosidicos, liberando celobiosa desde los extremos no reducidos de la cadena de la celulosa; y celobiosas conocidas también como $\beta$-glucosidasas, que catalizan la hidrólisis del disacárido celobiosa liberando a las glucosas (Henrissat, 1991; Lo Leggio y Larsen, 2001; Byrne et al.,1999).

La hidrólisis de la celulosa se lleva a cabo de diferente manera según la especie. En el caso de algunos microorganismos aeróbicos se produce una combinación de endo y exo- glucanasas, que si bien atacan al sustrato individualmente poseen una acción de sinergia entre ellas. Al mismo tiempo se ha visto que algunos organismos anaeróbicos, producen complejos multienzimáticos extracelulares que se encargan de la hidrólisis de la celulosa (Ohara et al., 2000; Calderón-Cortés et al., 2012; Tanimura et al., 2012; Tuyub-Tzuc et al., 2014).

Para intentar consensuar esta difícil actividad la Internacional Union of Biochemistry and Molecular Biology (1992) sugiere que la hidrólisis de los complejos celulósicos empiezan a degradarse por acción de las endoglucanasas que rompen los enlaces 1,4- $\beta$-glucosídicos lo cual reduce significativamente el grado de polimerización de la celulosa permitiendo que nuevos extremos de cadenas queden expuestos y faciliten el acceso para las exo-celobiasas que dan origen a unidades del disacárido celobiosa, el cual será hidrolizado por la enzima celobiasa originando moléculas unitarias de glucosa (Hui et al., 2002).

La celulosa es utilizada como una fuente nutricional por varios organismos, inicialmente se pensaba que únicamente microorganismos podrían degradarla pero en la actualidad se ha encontrado celulasas en varios grupos de animales. La tasa de absorción de nutrientes se basa en la tasa del contacto de los nutrientes con el epitelio intestinal. La inclusión de fibra en la dieta, como en el caso de celulosa, está asociada con mayor tiempo de permanencia del alimento en el estómago lo que contribuye a la utilización eficiente de proteína (Velurtas et al., 2011). De ahí, que la formulación de cualquier dieta requiere de una información detallada de los requerimientos nutricionales y capacidades digestivas de las especies. Los perfiles de actividad de las enzimas digestivas han sido utilizados para determinar las necesidades nutricionales de los crustáceos. 
Las enzimas celulasas se encuentran en una amplia gama de invertebrados como anélidos, moluscos, equinodermos y artrópodos (Crawford et al., 2004). Se ha demostrado que algunos invertebrados son capaces de degradar celulosa, celulasas microbianas pueden estar contribuyendo a los niveles de actividad enzimática observados en el sistema digestivo (Nakashima et al., 2002). En la última década se ha generado información sobre la presencia de celulasas en invertebrados, aunque en su mayoría atribuida a microorganismos simbiontes presentes en los tractos digestivos. Fueron Watanabe et al. (1998) quienes reportaron por primera vez la producción de una celulasa endógeno en Reticulitermes speratus Kolbe (Isoptera: Rhinotermitidae) y posteriormente ha habido otras investigaciones que han reportado celulasas endógenas en los órdenes Blattaria, Coleoptera, Hymenoptera, Hemiptera, Phthiraptera, and Orthoptera (Watanabe y Tokuda, 2010). Una distinción importante es que las celulasas endógenas de insectos se clasifican como endoglucanasas, la mayoría de la familia de la glicosil hidrolasas 9 (GHF9), mientras que las celulasas de origen microbiano reportadas son endo y exo- glucanasas y corresponden a otras familias de GHF (Watanabe y Tokuda, 2010). Actividad de celulosas ha sido detectada en langostas, cangrejos y cangrejos de río (Pavasovic et al., 2004). Directa evidencia de una secreción endógena de celulasa en un crustáceo ha sido demostrada gracias a estudios moleculares en el cangrejo rojo (Cherax quadricarinatus) y la presencia de una secuencia de cDNA de endo-1-4- $\beta$-glucanasa que se reporta en el hepatopáncreas de este artrópodo (Byrne et al.,1999; Tanimura et al., 2012).

En este trabajo, presentamos la identificación y caracterización preliminar de las celulasas del camarón Litopenaeus vannameien sus estadios larvario y adulto.

\section{MATERIALES Y MÉTODOS}

Obtención de la muestra.- En los ensayos se utilizaron camarones adultos y de los diferentes subestadios de $L$. vannamei colectados en los estanques de cría de las camaroneras de la Península de Santa Elena y Muisne, en las provincias de Santa Elena y Esmeraldas respectivamente.

En el caso de los adultos, se seleccionaron especímenes con un promedio de 8.0 a 10.0 gramos de peso corporal, con una curva de crecimiento de $1.0 \mathrm{~g} /$ semana, que fueron alimentados con un balanceado compuesto de $36 \%$ de proteína.

En el lugar de recolección se extrajeron los intestinos y hepatopáncreas mediante una incisión en la parte dorsal del animal. Dichas muestras fueron transportadas a $4^{\circ} \mathrm{C}$ hasta el Laboratorio de Biotecnología de la PUCE-Quito para los análisis respectivos.

En el caso de los subestadios larvarios, estos fueron recolectados en laboratorios de cría de camarón en la provincia de Santa Elena. Los subestadios colectados fueron: Zoea 1, 2 y 3; Mysis 1, 2 y 3; y poslarva 1, 2 y 6 . Los subestadios se clasifican según los días desde la eclosión del nauplio (Fao, 2006), y con esta base fueron clasificados por los laboratorios de cría de camarón que proveyeron las muestras.

Preparación de los homogeneizados de hepatopáncreas e intestinos.- El hepatopáncreas fue homogeneizado con agua destilada a 4 grados centígrados en el laboratorio, se utilizó un homogeneizador Braun-Melsungen de $5 \mathrm{~mL}$ de capacidad con punta de teflón. Para extraer la grasa del hepatopáncreas se procedió a dos procesos sucesivos de centrifugación (el primero a $12000 \mathrm{rpm}$ por $20 \mathrm{~min}$, seguido por $3000 \mathrm{rpm}$ durante $20 \mathrm{~min}$ ) mediante una centrífuga refrigerada Sorvall RC-5b (Lee et al., 1990). La grasa fue desechada y se extrajo el sobrenadante, llevándola a una concentración de 4 animales $/ \mathrm{mL}$. De igual manera, los intestinos fueron homogeneizados (Ultra-Turvax T25) y filtrados por una malla de nylon con un poro de 250 micras. La solución fue diluida hasta llegar a una concentración final de 6 animales $/ \mathrm{mL}$.

Preparación de los homogeneizados de los subestadios.- Las muestras de los diferentes subestadios de Litopenaeus vannamei se homogeneizaron sobre hielo, en $16 \mathrm{~mL}$ de agua destilada enfriada a $4^{\circ} \mathrm{C}$, en un homogeneizador Braun-Melsungen. Debido al reducido tamaño de los animales en los diferentes subestadios se homogenizó el animal completo (aprox. 400$3500 \mu \mathrm{m})$ (Rodgers et al., 2013). Los diferentes homogeneizados se filtraron a través de una malla de nailon con un poro de 250 micras. De esta manera se obtuvo un preparado inicial, para cada estadio, con una concentración de 40 a 50 animales / $\mathrm{mL}$, que se congeló a $-20^{\circ} \mathrm{C}$ en alícuotas de $6 \mathrm{~mL}$. El homogeneizado inicial se diluyó hasta 5 veces según la actividad enzimática en los diferentes estadios.

Cuantificación de proteína total.- La cuantificación de proteína total en las muestras analizadas se la realizó siguiendo el método de Bradford (1976), que utiliza albúmina de huevo como muestra estándar y métodos colorimétricos. Para preparar la proteína patrón se disolvieron $6 \mathrm{mg}$ de ovoalbúmina en 3 $\mathrm{mL}$ de agua destilada; esta solución de proteína se diluyó diez veces. El colorante se preparó 
disolviendo completamente $10 \mathrm{mg}$ de azul de Coomassie $\mathrm{G}$ en $5 \mathrm{~mL}$ de metanol, se añadieron 10 $\mathrm{mL}$ de ácido ortofosfórico $\left(\mathrm{H}_{3} \mathrm{PO}_{4}\right) 85 \%$ y se aforó a $100 \mathrm{~mL}$ con agua destilada. A cada tubo se le añadió $1 \mathrm{~mL}$ de colorante y después de 5 minutos se midió la absorbancia contra un blanco de agua $(100 \mu \mathrm{L})$ sometido al mismo procedimiento anterior con la utilización de un espectofotómetro Milton-Roy Spectronic 301 (Absorbancia 595 nm).

Determinación del ph óptimo de celulasas y cuantificación de la actividad enzimática.- En el caso de los adultos y los subestadios previo a la determinación de la actividad enzimática se determinó el pH óptimo al cual la actividad hidrolítica de la celulasa fue más evidente. Cada ensayo se realizó en triplicado en un rango de $\mathrm{pH}$ de 4.0 a 10.0, tomando intervalos de 0.5 unidades en el caso de los subestadios y adultos, en este último se amplió el rango básico hasta 11.0. Los valores de $\mathrm{pH}$ en el rango de $\mathrm{pH}$ se lograron usando diferentes tampones comunmente utilizados: citrato-fosfato ( $\mathrm{pH}$ 4.0-6.5), fosfato ( $\mathrm{pH} 7.0-8.5)$ y glicina- $\mathrm{NaOH}$ ( $\mathrm{pH}$ 10.5-11). La concentración final de los tampones fue de 0.05 M (Espinoza-Fuentes et al., 1984).

Se utilizó como sustrato carboximetil-celulosa (CMC)demediana viscosidad conuna concentración final de $0.5 \%$. Los tubos de reacción constaban, en el caso de los adultos, de $0.2 \mathrm{~mL}$ de sustrato, 0.2 $\mathrm{mL}$ de tampón $(0.2 \mathrm{M})$ a diferente $\mathrm{pH}(4.0-11.0)$ y $0.4 \mathrm{~mL}$ de extracto enzimático (hepatopáncreas e intestino). En el caso de los subestadios, las mezclas de reacción fueron de $0.5 \mathrm{ml}$ de sustrato, $0.5 \mathrm{~mL}$ de tampón $0.2 \mathrm{M}$ a diferente $\mathrm{pH}$ y $0.2 \mathrm{~mL}$ de extracto enzimático (homogeneizado de camarón). Los tubos fueron incubados en un baño maría a 30 grados centígrados por 30, 60, 90 y 120 minutos. Para detener la reacción enzimática se adicionaron $0.4 \mathrm{ml}$ de ácido 3.5 dinitrosalicílico (DNS), se agitó la solución y se lo llevó inmediatamente a ebullición. Los tubos fueron enfriados hasta temperatura ambiente, se añadieron $0.4 \mathrm{~mL}$ de agua destilada en el caso de los subestadios larvarios y $0.4 \mathrm{~mL}$ en el caso de los adultos y se procedió a la cuantificación por espectrofotometría. Para los ensayos se establecieron muestras blancos en las cuales el volumen correspondiente al extracto enzimático se remplazó por el mismo volumen de agua destilada. La absorbancia de las muestras se midió mediante espectrofotometría a $540 \mathrm{~nm}$ contra una muestra blanco de agua destilada sometida al mismo tratamiento (Espinoza - Fuentes et al., 1984).

En la preparación del ácido 3-5 dinitro-salicílico se disolvió $1 \mathrm{~g}$ de ácido 3-5 dinitro-salicílico en $20 \mathrm{~mL}$ de hidróxido de sodio $(\mathrm{NaOH}) 2 \mathrm{~N}$; se añadieron $50 \mathrm{~mL}$ de agua destilada para lograr una buena disolución. Inmediatamente se añadieron
$30 \mathrm{~g}$ de tartarato de sodio y se aforó a $100 \mathrm{~mL}$. La actividad de la celulasa se determina en función de la cantidad de los grupos reductores liberados, la coloración será más intensa mientras mayor sea la actividad hidrolítica, y por lo tanto la absorbancia detectada por espectrofotometría será mayor (Espinoza - Fuentes et al., 1984).

Una vez determinados los valores de $\mathrm{pH}$ en los cuales la absorbancia era mayor y por lo tanto el $\mathrm{pH}$ óptimo para la actividad hidrolítica de la enzima, se procedió a cuantificar la actividad enzimática relativa expresada en términos de mUnidades (mU/animal). Una unidad de enzima es la cantidad de enzima que hidroliza una nanomol de sustrato por minuto.

La concentración de enzima presente en las muestras ensayadas se obtuvo relacionando la pendiente de cada ensayo con el factor de absorción del sustrato, la cantidad de enzima utilizada en $\mathrm{mL}$ y el factor de dilución de la muestra para obtener la actividad enzimática relativa en $\mathrm{mU} / \mathrm{mL}$. Una vez cuantificada la cantidad de proteína para cada muestra de extracto, la actividad específica (mU/ $\mathrm{mg}$ ) se obtiene del cociente entre la actividad relativa ( $\mathrm{mU}$ / animal) y la concentración de proteína total (mg/animal). Los ensayos de actividad enzimática se realizaron en el $\mathrm{pH}$ determinando para cada muestra y se utilizó CMC como sustrato, tampón al $\mathrm{pH}$ óptimo y el extracto enzimático de hepatopáncreas, intestino o del subestadio larvario. Se utilizaron blancos de sustratos (sin extracto enzimático) y de enzima ( se sometió al mismo tratamiento. Cada ensayo se realizó por triplicado.

Actividad enzimática en camarones vivos adultos en presencia de antibióticos.- Únicamente para los camarones vivos adultos se realizaron ensayos con (67) camarones vivos con un peso entre 8 y 10 $\mathrm{g}$ para eliminar la presencia de microorganismos productores de celulasa. Los especímenes fueron colectados y posteriormente transportados en agua de mar para su cultivo en el Laboratorio de Biotecnología de la Pontificia Universidad Católica del Ecuador. Los camarones se mantuvieron en peceras de 40 litros de agua con salinidad del $3 \%$, a una temperatura de $22^{\circ} \mathrm{C}$ y aireación constante. La alimentación usada fue balanceado comercial con $36 \%$ de proteína. En el tiempo cero del ensayo se sacrificaron dos especímenes y se cuantificó la presencia de celulasa en el hepatopáncreas. Para descartar o evidenciar la presencia de crecimiento microbiano se sembraron muestras de hepatopáncreas en agar nutriente, medio selectivo para Pseudomonas, TCBS (medio selectivo para Vibrio), Cetrimide (selectivo para Pseudomonas), Caseina Peptina y Sauboraud $2 \%$ de glucosa 
(hongos) y se los evaluó. A todos los medios se les adicionó $3 \%$ de sal $(\mathrm{NaCl})$.

Determinación de dosis de antimicrobianos.Para eliminar en lo posible a los microorganismos presentes en el cultivo del camarón y que podrían estar contribuyendo a la actividad de celulasa identificada, se realizaron pruebas de sensibilidad con las bacterias aisladas del hepatopáncreas. Los antimicrobianos ensayados fueron: eritromicina (30 $\mathrm{mg}$ ), ácido oxalínico (10 mg) nitrofurantoína (50 $\mathrm{mg})$, cloranfenicol (50 mg), tetraciclina (30 mg) y sulfatrimetroprim (25 mg). El nivel de sensibilidad se basó en la medición de halos de inhibición de crecimiento bacteriano alrededor del disco de antibiograma bajo el método de Bauer-Kirby (1966).

A partir de los resultados de las pruebas de sensibilidad, se realizó un control de supervivencia con un individuo, al cual se le colocó en una pecera con 50 ppm del antimicrobiano demayor sensibilidad y $1 \mathrm{~mL} / \mathrm{L}$ de albendanzol (antiprotozoo). Se repitió la dosis cada seis horas en el caso de los antibióticos y una vez al día con el albendazol. Se sacrificó al individuo y se extrajo el hepatopáncreas para comprobar el efecto de los antimicrobianos.

Posteriormente se realizó el mismo proceso con 20 camarones en un período de cinco días con la misma frecuencia la frecuencia de administración de antimicrobianos y albendazol para el control. Los especímenes fueron sacrificados, su hepatopáncreas fue extraído y se llevó a una concentración final de 1.2 hepatopáncreas/mL (sin antibiótico) y 2.5 hepatopáncreas / $\mathrm{mL}$ (con antibiótico).

Este experimento se lo realizó nuevamente en el laboratorio comercial AQUALAB S.A en la península deSanta Elena con camarones adultos con un promedio de $5 \mathrm{~g}$ con la finalidad de ensayar con especímenes tratados previamente con probióticos en las piscinas de crecimiento. Se utilizaron las mismas concentraciones de antibióticos aplicadas a los camarones en el Laboratorio de la PUCE. La única diferencia fue el uso del quimioterapeútico líquido Trifluralin con dosis de 10 ppm, dos veces al día en lugar de albendazol. Los hepatopáncreas fueron extraídos y homogeneizados según los procedimientos anteriores con una concentración final de 2.6 hepatopáncreas / $\mathrm{mL}$ (sin antibiótico) y 3.1 hepatopáncreas $/ \mathrm{mL}$ (con antibiótico).

\section{RESULTADOS}

pH óptimo de celulasas en homogenizado de subestadios larvarios.- Se tuvo dificultad en determinar el $\mathrm{pH}$ óptimo de la actividad de celulasa en los homogeneizados debido a un comportamiento irregular de la enzima en los ensayos en todos los estadios larvarios ensayados. Para establecer la actividad en función del $\mathrm{pH}$, se eligió el estadio en el cual su actividad fue estable y regular para la realización de los ensayos, en este caso el subestadio zoea 3. En este subestadio se determinó que el tiempo total de incubación óptimo para cuantificar la actividad fue de 240 minutos en cuatro intervalos de 60 minutos y se determinó un rango amplio de $\mathrm{pH}$ - entre $\mathrm{pH} 6.5$ y $\mathrm{pH} 9.5$ - en el cual se evidenció actividad celulásica (Figura 1).

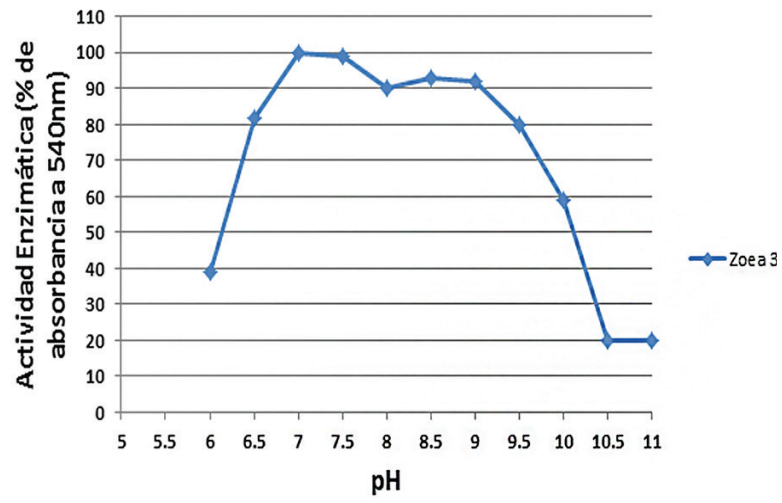

Figura 1. Curva de $\mathrm{pH}$ óptimo de la enzima celulasa en el subestadio Zoea 3 del camarón Litopenaeus vannamei. La actividad de la celulasa se presenta en un rango de $\mathrm{pH}$ de 6 a 9.5

pH óptimo de celulasas en hepatopáncreas e intestino.En las muestras de hepatopáncreas de camarón adulto se determinaron dos $\mathrm{pH}$ óptimos: uno en el rango ácido ( $\mathrm{pH} 4-6)$ y otro en el rango básico ( $\mathrm{pH}$ 10-11), mientras que en el intestino se observó únicamente el pH ácido ( $\mathrm{pH} 4-6)$. (Figura 2).

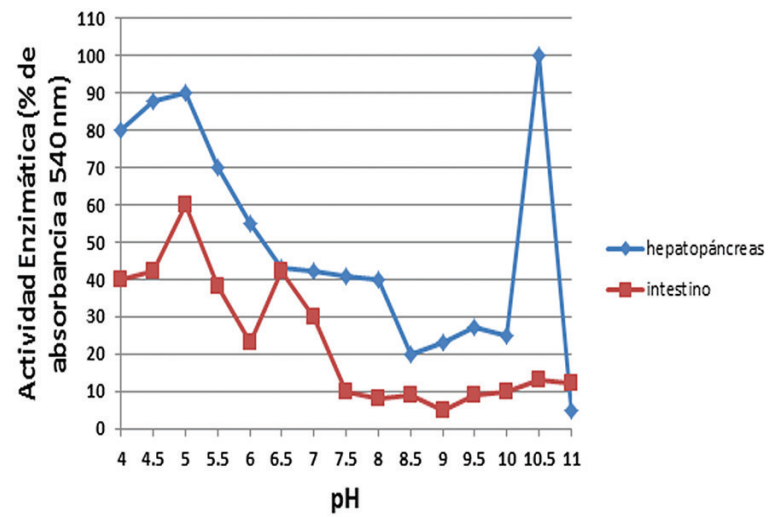

Figura 2. Curva de $\mathrm{pH}$ óptimo de la enzima celulasa en el hepatopáncreas e intestino del camarón adulto Litopenaeus vannamei

Cuantificación de la actividad enzimática.- El registro de absorbancia después de los intervalos de incubación con las mezclas de reacción fue irregular por lo cual, a pesar de tener evidencia de 
actividad de celulasa no se cuantificó la actividad relativa de la celulasa en los estadios larvarios. El subestadio en el cual se evidenció mayor estabilidad de la actividad fue el subestadio zoea 3 . En todos los ensayos la actividad de la enzima fue baja.

Los datos de cuantificación de actividad enzimática de las muestras en sus pH óptimos se reportan en la tabla 1. La actividad relativa ( $\mathrm{mU} /$ animal) nos indica que la actividad de las dos especies enzimáticas ( $\mathrm{pH} 5$ y pH 10)) en el hepatopáncreas es similar, indicando que las dos podrían ser producidas en este órgano; la actividad de la especie enzimática del intestino es tres veces menor a las del hepatopáncreas. Al determinar la actividad en función de la cantidad de proteína presente en la muestra (actividad específica) se observa una mayor actividad de la enzima en el intestino que las dos presentes en el hepatopáncreas. Esto sugiere que en el intestino la actividad detectada podría ser la suma de la actividad de la enzima del hepatopáncreas $(\mathrm{pH}$ ) que viaja al intestino y la actividad celulásica del aporte de microorganismos asociados al intestino. Esta observación se respalda por los ensayos realizados con el camarón cultivado en el Laboratorio de Biotecnología de la PUCE como en el laboratorio comercial en la Península de Santa Elena, en los cuales la actividad específica de la celulasa es mayor en las muestras tratadas con antimicrobianos con relación a las muestras no tratadas, lo cual indica que sí hay un aporte de parte de microorganismos asociados en cuanto a la actividad de celulasa en el camarón.

Análisis microbianos.- Después de 24 horas de cultivo se observó crecimiento bacteriano en Agar nutriente, cetrimide, TCBS agar, y en el agar selectivo para Pseudomonas. En los antibiogramas, los antibióticos de mayor sensibilidad fueron nitrofurantoína y ácido oxalínico.

\section{DISCUSIÓN}

La nutrición de los organismos marinos es esencial para una acuacultura rentable, por lo cual los tipos y las propiedades de las enzimas digestivas del camarón definen las capacidades digestivas y por tanto sugieren los ingredientes que deben ser incluidos en las dietas para reproducir las condiciones de la alimentación de los crustáceos en condiciones naturales. Sin embargo, el proceso de elaboración de dietas, en la mayoría de los casos, no ha incluido información sobre las condiciones fisiológicas y bioquímicas del camarón (NarváezTrujillo, 1990). Las especies de camarones son omnívoros con amplias capacidades bioquímicas para poder degradar las fuentes de energía de su ambiente natural. El principal recurso energético de este crustáceo es la proteína seguido por los carbohidratos como energía metabólica. Adicionalmente necesita lípidos como elementos fundamentales en la función y estructura celular (Gaxiola et al., 2006).

Los metazoos son capaces de digerir la celulosa gracias a la presencia de microorganismos simbiontes (bacterias, hongos y protozoos) que proporcionan a sus hospederos habilidades digestivas adicionales (Hood, 1971; Cutter y Rosenberg, 1971; Mangrove, 1988; Byrne et al., 1999). El modelo enzimático más conocido se basa en el sistema de hongos donde se demuestra su complejidad basada en acciones poligénicas, conjuntos multienzimáticos y estructuras mixtas formadas entre celulasas y proteínas, glicoproteínas o polisacáridos (Eveleigh, 1987).

En el caso de crustáceos, el proceso digestivo se lleva a cabo en el hepatopáncreas y en el intestino medio con funciones y actividades diferentes en dichos órganos. La celulasa actúa en la digestión primaria

Tabla 1. Actividad relativa ( $\mathrm{mU} /$ animal) y específica $(\mathrm{mU} / \mathrm{mg})$ de celulasas en las muestras de adulto analizadas*

\begin{tabular}{cc}
\hline MUESTRAS & mU/Animal \\
Muestras sin tratamiento & $30.5 \pm 2.8$ \\
Hepatopáncreas (pH 5) & $33.3 \pm 5.0$ \\
Hepatopáncreas (pH 10.5) & $8.3 \pm 0.6$ \\
Intestino (pH 5) & 8.9 \\
Muestras tratadas en el Laboratorio de Biotecnología & $140.9 \pm 6.0$ \\
Hepatopáncreas con tratamiento antimicrobiano & 13.4 \\
Hepatopáncreas sin tratamiento antimicrobiano & 34.9 \\
Muestras tratadas en las Camaroneras de Sta. Elena & $11.0 \pm 2.0$ \\
Hepatopáncreas con tratamiento antimicrobiano & $25.2 \pm 0.5$ \\
Hepatopáncreas sin tratamiento antimicrobiano & 2.9 \\
\hline
\end{tabular}

\footnotetext{
*Se reporta la media de tres determinaciones.
} 
iniciando su actividad en el hepatopáncreas para posteriormente volver a activarse en el intestino medio. En insectos se ha propuesto una recirculación de enzimas que puede ser aplicado también a los crustáceos (Espinoza-Fuentes et al., 1984)

La actividad celulolítica detectada en el desarrollo ontogénetico del camarón fue baja e inestable, una condición reportada también en el análisis comparativo de enzimas digestivas en cuatro especies de crustáceos incluyendo dos especies de Penaeus realizada por Luqing (1997). A pesar de evidenciar actividad celulolítica, la inestabilidad en la actividad a lo largo del tiempo de desarrollo de los ensayos y la baja actividad observada no permitió cuantificar la actividad relativa. El pH óptimo determinado en el rango de 6.5 a 9.5 sugiere que puede haber una mezcla heterogénea de enzimas por un origen múltiple de los extractos obtenidos considerando que en los tanques de cultivo hay larvas provenientes de nauplios desovados a partir de diferentes hembras ovadas; por otro lado, este amplio rango de $\mathrm{pH}$ observado puede indicar la presencia de enzimas producidas por la larva y/o por microorganismos asociados, a pesar del uso y aplicación de antibióticos en los tanques de cría (Narváez-Trujillo, 1990).

En el caso del adulto, se encontró actividad enzimática para celulasas a dos pHs: 5.0 y 10.5 en el hepatopáncreas y de $\mathrm{pH} 5.0$ en el intestino (SegoviaSalcedo, 1996). La actividad relativa (mU/animal) de las dos enzimas del hepatopáncreas es similar y cada una de estas tienen una actividad tres veces mayor a la encontrada en el intestino. Estos resultados sugieren la presencia de dos posibles celulasas, una de ellas podría ser transportada desde el hepatopáncreas al intestino. Los datos de actividad de celulasa con un rango ácido concuerdan con lo observado en estadio larvario (Narváez-Trujillo, 1990). Una alternativa a esta interpretación es que hay la producción de una celulasa en el hepatopáncreas que tiene dos rangos de $\mathrm{pH}$ para su actividad, en este caso aún se sostiene la posibilidad que la enzima del hepatopáncreas se movilice al intestino y actúe a un pH más ácido que la del hepatopáncreas. En ninguno de los dos casos se invalida la participación de actividad celulásica por parte de microorganismos asociados como sucede en otros crustáceos (Zimmer et al., 2002).

Celulasas de origen fúngico y microbiano presentan actividad enzimática dentro de los rangos encontrados en el intestino (pH 5) (Wang et al., 1994; Guillén et al., 1987; Kaya et al., 1994; Copa-Patiño et al., 1987; Espinoza-Fuentes et al., 1984; Tuyub-Tzuc et al., 2014). Adicionalmente, la actividad enzimática de los extractos provenientes de los organismos tratados con antimicrobianos, antifúngicos y antiprotozoarios disminuyó en relación a las muestras no tratadas (Tabla 1) apoyando la hipótesis que la celulasa activa a $\mathrm{pH}$ ácidos ( $\mathrm{pH}$ 4-6) puede tener un origen fúngico o microbiano. Estos resultados concuerdan con los datos de bacterias aisladas del tracto digestivo de Penaeus aztecus que describen a una o más celulasas junto con lipasas, amilasas y quitinasas (Dempsey y Kitting, 1987). Esta capacidad multienzimática sugiere un alto potencial de degradación por parte de estas colonias microbianas. Pero su funcionalidad va a estar restringida a las condiciones ambientales del tracto digestivo $(\mathrm{pH}$, niveles de oxígeno, disponibilidad de nutrientes (Tuyub-Tzuc et al., 2014).

En el caso de la celulasa con actividad a pH básico (10.5) puede tratarse de una celulasa producida de manera endógena por el camarón. Estos datos son apoyados por lo encontrado por Byrne et al. (1999) que identificó el cDNA de una endo-1,4-betaglucanasa de 469 aminoácidos, denominada CqEG, generada en el hepatopáncreas del crustáceo Cherax quadricarinatus. Este gen es similar en estructura a los encontrados en los genes de endoglucanasas funcionales de cucarachas y termitas (Watanabe y Tokuda, 2001). Estudios de comparación genética han identificado a estos genes pertenecientes a la familia de glicosil hidrolasas (GFH) 9 celulasas (Byrne et al., 1999) similares a los encontrados en termitas lo cual sugiere un origen común entre las células de insecto con la de crustáceos. Es posible que las enzimas de celulasas hayan evolucionado en diferentes linajes de los crustáceos en relación con sus preferencias alimenticias principalmente en los herbívoros (Crawford et al., 2004).

Las evidencias observadas en este estudio favorecen la combinación de enzimas celulósicas endógenas y simbióticas para la digestión de la pared celular vegetal en $L$. vannamei. La participación cooperativa de celulasas de diferentes fuentes (simbiontes y hospederos) con diferentes características enzimáticas proveen de un mecanismo exitoso de digestión de dietas ricas en celulosa (Tanimura et al., 2012). De igual manera debemos tomar en cuenta que la composición de la flora bacteriana varía con la dieta ya que un porcentaje de microorganismos ingresan al tracto digestivo con la comida. De ahí, la importancia de estudios más profundos sobre la comunidad microbiana permanente y la itinerante asociada al camarón y las capacidades enzimáticas de cada una de ellas. Este estudio no descarta la posibilidad que las fuentes de celulasas no sean efectivamente de microorganismos resistentes a los antimicrobianos utilizados. 
Los datos reportados en este estudio sobre las capacidades de producción enzimática del camarón pueden ser la base para futuros proyectos de investigación cuyo objetivo sea optimizar los procedimientos de cultivo de camarón. La identificación de altos niveles de actividades de carbohidrasas como las celulasas sugiere la presencia de materiales vegetales en la dieta de L. vannamei, lo cual está relacionado con la presencia de algas como fuente alimenticia en estos invertebrados filtradores. Estudios específicos son necesarios para definir formulación de dietas específicas para el camarón considerando tanto la microbiota como las enzimas endógenas del sistema digestivo. Futuras investigaciones en estas áreas pueden reducir los costos de producción y mejorar los niveles de digestión de las dietas.

\section{REFERENCIAS BIBLIOGRÁFICAS}

Bauer AW, Kirby WMM, Sherris JC y Turck M. 1966. Antibiotic susceptibility testing by a standardized single disk method. American Journal of Clinical Pathology, 36:493-496.

Beilen JB y Li Z. 2002. Enzyme Technology: an overview. Current Opinion in Biotechnology, 13, 338-344.

Bradford M. 1976. A Rapid and sensitive method for the quantification of microgram quantitites of protein utilizing the principle of protein-dye binding. Analytic Biochemistry, 72:248-254.

Byrne KA, Lehnert SA, Johnson SE y Moore SS. 1999. Isolation of a cDNA encoding a putative cellulose in the red claw crayfish Cherax quadricarinatus. Gene, 239: 317-324.

Copa-PatiñoJL, Monistrol Y,Laborada Fy Pérez-Lebic. 1987. Characterization of 1,3 Beta-Glucanasas poroduced during autolisis of Penicillium oxalicum in different culture media. Transaction of British Mycology Society, 88(3):317-321.

Crawford AC, Kricker JA, Anderson AJ, Richardson NR y Mather PB. 2004. Structure and function of a cellulose gene in redclaw crayfish Cherax quadricarinatus. Gene, 340: 267-274.

Cutter MF y Rosenber F. 191. The role of cellulolytic bacteria in the digestive process of the shipworm. II. Isolation and some properties of marine bacterial cellulose. Marine Organisms, 7:225-229.
Dempsey A y Kitting C. 1987. Characteristics of bacteria isolated from penaid shrimp. Crustaceana, 52:90-94.

Espinoza-Fuentes F, Ferreira C y Terra W. 1984. Spatial organization of digestion in the larval and imaginal stages of the Sciarid fly, Trichosia pubescens. Insect Biochemistry, 14(6):631-638.

Espinoza-Fuentes F y Terra W. 1986. Properties of larval and imaginal membrane-bound digestive enzymes from Trichosia pubescens. Archives of Insect Biochemistry and Physiology, 3:181-192.

Fao. 2006. Cultured Aquatic Species Information Programme. Penaeus vannamei. Cultured Aquatic Species Information Programme. Text by Briggs, M. In:FAO Fisheries and Aquaculture Department [online]. Rome. Updated 7 April 2006. [Cited 29 July 2015]. http://www. fao.org/ fishery/culturedspecies/Penaeus_ vannamei/en

Galante YM y Formantici C. 2003. Enzyme Application in Detergency and in Manufacturing Industries. Current Organic Chemistry, 7:1399-1422.

Gaxiola G, Rosas C, Arena L y Cuzón G. 2006. Requerimiento de carbohidratos. En: Rosas C. Carrillo O. Wilson R. Andreatta ER (eds) Estado actual y perspectivas de la nutrición de los camarones peneidos en Iberoamèrica. Mèxico DF, pp 143-153.

Guillén F, Reyes F, Rodríguez J y Vásquez C. 1987. Induction of an extracelular cellulase system during autolysis of Alternaria alternata. Transaction of British Mycology Society, 89(1):35-39.

Henrissat B. 1991. A classification of glycosyl hydrolases based on amino acid sequence similarities. Biochemistry Journal, 280:309-316.

Hood M, Meyer P y Colmer A. 1971. Bacteria of the digestive tract of the white shrimp Penaus setferusi. Bacteriology Proceedings, 71:48.

Hui JPM, White TC y Thibault P. 2002. Identification of glycan structure and glycosylation sites in cellobiohydrolase II and endoglucanase I and II from Trichoderma ressei. Glycobiology, 12:837-849.

Kaya F, Heitmann J y Joyce T. 1994. Cellulase binding to cellulose fibers in high shear fields. Journal of Biotechnology, 36:1-10. 
Lo Leggio L y Larsen S. 2002. The 1.62 A structure of Thermoascus aurantiacus endoglucanase: completing the structural picture of subfamilies in glycoside hydrolase family 5. FEBS Letters, 523:103-108.

Luqing P. 1997. Comparative studies on digestive enzyme activities during larval development of four species of shrimps and crabs. Journal of Ocean University of Qingdao, 3.

Mangrove R. 1998. Digestive ability of freshwater crayfish Paranephrops zealandicus (White) (parastacidae) and the role of microbial enzymes. Freshwater Biology, 20:305-314.

Marín Alvarado RM. 2007. Caracterización y Expresión Recombinante de una Celulasa de Origen Antártico. Universidad de Chile. Facultad de Ciencias Físicas y Matemáticas.

Nakashima K, Watanabe H, Saitoh H, Tokuda G y Azuma JI. 2002. Dual cellulose-digestive systemof the wood-feeding termite Coptotermes formosanus Shikari. Insect Biochemistry and Molecular Biology, 32:777-784.

Narváez-Trujillo A. 1990. Identificación y cuantificación de la enzima tripsina, aminopeptidasa y amilasa responsables de la digestión primaria en el camarón (Penaeus vannamei), cultivado en los laboratorios de producción de lava en la provincia de Guayas, Ecuador. Tesis de Licenciatura en Ciencias Biológicas, Pontificia Universidad Católica del Ecuador. Quito, Ecuador.

Ohara H, Noguchi J, Karita S, Kimura T, Sakka K y Ohmiya K. 2000.Sequence of eg Vand Properties of Eg V, a Ruminococcus albus Endoglucanase Containing a Dockering Domain. Bioscience, Biotechnology and Biochemisty, 64:80-88.

Pvasovic M, Richardson NA, Anderson AJ, Mann D y Mather PB. 2004. Effect of $\mathrm{pH}$, temperature and diet on digestive profiles in the mud crab, Scylla serrata. Aquacultura, 242:641-654.

Rodgers GC, Roberts SD y Dixon CD. 2013. The effects of temperature on larval size in the western king prawn, Peaneus (Melicertus) latisulcatus Kishinouye, from Spencer Gulf, South Australia: implications for fishery management. Marine and Freshwater Research, 64:976-985.
Segovia-Salcedo MC. 1996. Celulasas presentes en el Intestino Medio y el Hepatopáncreas de Penaeus vannamei cultivado en la Costa Ecuatoriana. Tesis de Licenciatura en Ciencias Biológicas, Pontificia Universidad Católica del Ecuador. Quito, Ecuador.

Tanimura A, Liu W, Yamada K, Kishida T y Toyohara H. 2012. Animal Cellulases with a focus on aquatic invertebrates. Fisheries Sciences, 79:1-13.

Tuyub-Tzuc J, Rendìz-Escalante D, RojasHerrera R, Gaxiola Cortés G y Arena-Ortiz MA. 2014. Microbiata from Litopenaeus vannmaei:digestive tract microbial community of Pacific White shrimp (Litopenaeus vannamei). Springer Plus, 3:280.

Velurtas SM, Díaz AC, Fernández-Giménez AN y Fenucci JL. 2011. Influence of dietary starch and cellulose levels on the metabolic profile and apparent digestibility in penaeoid shrimp. Latin American Journal of Aquatic Research, 39(2) 214-222.

Wang YL, Cracker L y Zhongyuan M. 1994. Purification and characterization of cellulose from leaf absicion zones of coleus. Plant Physiology Biochemistry, 32(4): 467-472.

Watanabe H y Tokuda G. 2010. Cellulolytic systems in insects. Annual Review of Entomology, 55:609-632.

Watanabe H, Noda H, Tokuda G y Lo N. 1998. A cellulase gene of termite origin. Nature, 394:330-331.

Zimmer M, Danko JP, Pennings SC, Danford AR, Carefoot TH, Ziegler A y Uglow RF. 2002. Cellulose digestion and phenol oxidation in coastal isopods (Crustacea:Isopoda). Marine Biology, 140:1207-1213. 